\title{
Enterovirus en aguas naturales de Valparaíso: una propuesta metodológica para su análisis
}

\author{
Enterovirus in Valparaiso natural water resources: a methodological proposal for its analysis \\ Maritza Soler ${ }^{1}$, Soledad Lobos ${ }^{2}$, Marcos Lorca ${ }^{3}$ y Ema Navarrete ${ }^{4}$ \\ ${ }^{1}$ Depto. de Química y Bioquímica, Facultad de Ciencias, Universidad de Valparaíso, \\ Gran Bretaña 1111 Playa Ancha, Valparaíso, Chile \\ ${ }^{2}$ Depto. de Ciencias Químicas y Recursos Naturales, Facultad de Farmacia, Universidad de Valparaíso, \\ Gran Bretaña 1093 Playa Ancha, Valparaíso, Chile \\ ${ }^{3}$ Tesista Proyecto DIPUV 04/2001, Facultad de Ciencias Naturales y Exactas, Universidad de Playa Ancha, \\ Leopoldo Carvallo 270, Playa Ancha, Valparaíso, Chile \\ ${ }^{4}$ Depto. de Pre-Clínica, Facultad de Medicina, Universidad de Valparaíso, \\ Hontaneda 2653, Valparaíso, Chile \\ Maritza.Soler@uv.cl
}

\begin{abstract}
In Chile, water sanitary quality is determined by the concentration of fecal indicator bacteria. However, numerous investigations have shown that achieving minimum fecal coliform standards do not predict viral contamination, such as enteric viruses. Enteroviruses are microorganisms causing several infections and massive outbreaks of illness which represent a serious risk for public health. In the present study, performed during 2001-2003 in Valparaiso, central Chile, natural water samples were collected from five streams and
\end{abstract}

\section{Introducción}

El agua es un recurso natural, único y escaso, esencial para la vida e indispensable para el hombre. La calidad del agua tiene directa relación con la salud de las personas. Su mal o indiscriminado uso puede provocar la contaminación del recurso con el consecuente deterioro de la calidad de los demás recursos naturales. El control de la presencia de los virus entéricos en las aguas del medio ambiente, comenzó en la década de 1940 con la finalidad de vigilar la calidad microbiana y de dilucidar las principales fuentes de contaminación de éstas (Griffin et al. 2001).

Los enterovirus (EVs) (género Enterovirus, familia Picornaviridae) están entre los virus más comunes que infectan a los seres humanos. La mayoría de estas infecciones no presenta síntomas o bien origina cuadros febriles o respiratorios suaves. Sin embargo, también pueden producir una amplia variedad de enfermedades clínicas, como conjuntivitis hemorrágica aguda, meningitis aséptica, erupciones difusas, parálisis aguda flácida y miocarditis (Fong \& Lipp 2005). Debido a que se multiplican en el tracto gastrointestinal, los individuos processed for enterovirus detection by tissue culture and reverse transcription (RT) associated to polymerase chain reaction (PCR). None enterovirus was found in any of the natural stream waters. Simulation of an infection, in drinking water and water from one stream was used to check RT-PCR detection of enterovirus.

Key words: Aquatic pollution, cell culture, RT-PCR, public health, virus infections

infectados los excretan en altas concentraciones $\left(10^{5}-10^{11}\right.$ por gramo) en las heces y así a través de la descarga de desechos pueden ser dispersados al ambiente acuático (Abbaszadegan 2001).

Los virus entéricos son muy estables en el medio ambiente, toleran el cloro proveniente del tratamiento de aguas residuales (Keswick et al. 1984) y un amplio rango de temperaturas y salinidades (Skraber et al. 2004), todo lo cual facilita su supervivencia en el medio acuático. En el agua, los virus generalmente son los patógenos con el mayor grado de dilución y por ello requieren de métodos de concentración para lograr su detección (Straub \& Chandler 2003). Por contraste, los moluscos son contaminados con enterovirus más fácilmente (Vinatea et al. 2006), debido a su modo de alimentación que filtra y concentra el alimento y cuando son consumidos crudos representan un alto riesgo para la salud de la población.

Los métodos para detectar enterovirus en muestras ambientales son generalmente de dos tipos, aquellos basados en la infectividad a cultivos celulares y las técnicas moleculares. Estas muestras, en especial los lodos urbanos, contienen numerosos compuestos orgánicos e inorgánicos (ácidos húmico y fúlvico, polifenoles y 
metales pesados) que son tóxicos (Muller-Wegener 1988) y producen lisis de los cultivos celulares e inhiben la transcripción reversa (TR) y la reacción de la polimerasa en cadena (RPC). Esto es especialmente importante en las muestras ambientales de agua que se deben concentrar para analizarlas y al hacerlo también se concentran compuestos que pueden interferir en los procedimientos. El propósito de este trabajo fue plantear la necesidad de un control virológico en aguas naturales de Valparaíso, Chile central, a través de la detección de virus entéricos, usando las técnicas de cultivo celular y transcripción reversa asociada a la reacción de la polimerasa en cadena (TR-RPC). Este análisis se hace por primera vez en estos cursos hídricos de Valparaíso y con ello se busca contribuir a la vigilancia de la contaminación ambiental en aguas naturales de Chile.

\section{Material y métodos}

\section{Áreas de muestreo}

El estudio se desarrolló en Chile central (región de Valparaíso), entre septiembre de 2001 y mayo de 2003 (Tabla 1). Se recolectó agua de los esteros Tunquén

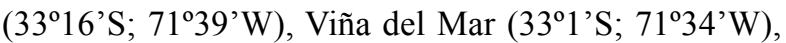

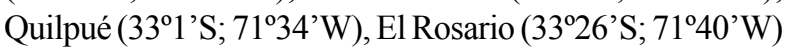

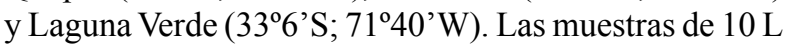
de agua se envasaron en contenedores de vidrio de $5 \mathrm{~L}$ y se transportaron al Laboratorio de Química Analítica de la Facultad de Farmacia, de la Universidad de Valparaíso, para ser procesadas. Previo al muestreo, los envases se ambientaron con el agua del sector, para no modificar las condiciones fisicoquímicas de ésta. Las muestras de agua fueron analizadas en los siguientes aspectos:

\section{Parámetros fisicoquímicos}

El pH y la conductividad eléctrica se determinaron en duplicado en cada sitio de muestreo. La dureza total, sólidos totales y suspendidos se determinaron según protocolo recomendado (INN 1996).

\section{Determinación de metales}

La determinación de $\mathrm{Fe}$, $\mathrm{Se}, \mathrm{As}, \mathrm{Zn}, \mathrm{Pb}, \mathrm{Cu}$ y $\mathrm{Cd}$ se realizó en un espectrómetro de Emisión Atómica con Plasma Inductivamente Acoplado (ICP-OES) Optima 2000 DV, Perkin Elmer.

Tabla 1

Muestras de agua recolectadas en distintas fechas y localidades en Chile central. Se indican (X) las muestras tratadas con $\mathrm{MgCl}_{2}$ y/o $\mathrm{Al}\left(\mathrm{NO}_{3}\right)_{3}$ para la concentración de virus

Water samples collected in different dates and locations in central Chile. Samples treated with $\mathrm{MgCl}_{2}$ and/or $\mathrm{Al}\left(\mathrm{NO}_{3}\right)_{3}$ for virus concentration are indicated (X)

\begin{tabular}{|c|c|c|c|c|}
\hline Mes y año de muestreo & Sitios de muestreos & Sector & $\mathrm{MgCl}_{2}$ & $\mathrm{Al}\left(\mathrm{NO}_{3}\right)_{3}$ \\
\hline \multirow[t]{2}{*}{ Septiembre 2001} & Estero de Tunquén & Sector Alto & $\mathrm{X}$ & \\
\hline & Estero de Tunquén & Desembocadura & $\mathrm{X}$ & \\
\hline \multirow[t]{2}{*}{ Octubre 2001} & Estero de Viña, & Puente Libertad & $\mathrm{X}$ & $\mathrm{X}$ \\
\hline & Estero de Quilpué & & $\mathrm{X}$ & $\mathrm{X}$ \\
\hline \multirow[t]{2}{*}{ Enero 2002} & Estero de Viña & Puente Libertad & $\mathrm{X}$ & $\mathrm{X}$ \\
\hline & Estero de Quilpué & & $\mathrm{X}$ & $\mathrm{X}$ \\
\hline \multirow[t]{4}{*}{ Abril 2002} & Estero El Rosario & Parte Alta & $\mathrm{X}$ & $\mathrm{X}$ \\
\hline & Estero El Rosario & Parte Baja & $\mathrm{X}$ & $\mathrm{X}$ \\
\hline & Estero de Laguna Verde & Puente Bajo & $\mathrm{X}$ & $\mathrm{X}$ \\
\hline & Estero de Laguna Verde & Puente Los Azules & $\mathrm{X}$ & $\mathrm{X}$ \\
\hline \multirow[t]{2}{*}{ Mayo 2003} & Estero de Laguna Verde & Puente Bajo & $\mathrm{X}$ & \\
\hline & Estero de Laguna Verde & Puente Los Azules & & $\mathrm{X}$ \\
\hline
\end{tabular}




\section{Concentración de las muestras}

A dos litros de cada muestra pre-filtrada (filtros de borosilicato GS50 de 1,2 $\mu \mathrm{m}$ ) se les agregó $\mathrm{MgCl}_{2} \mathrm{o}$ $\mathrm{Al}\left(\mathrm{NO}_{3}\right)_{3}$ (Tabla 1) de modo de alcanzar una concentración final $0,05 \mathrm{M}$. Después se dejaron a $4^{\circ} \mathrm{C}$ con agitación por $24 \mathrm{~h}$ para luego filtrarlas (Millipore GS de $0,22 \mu \mathrm{m}$ de nitrato de celulosa). Posteriormente para eluir los virus, cada filtro se sumergió en $5 \mathrm{~mL}$ de una solución de glicina $0,02 \mathrm{M}$ a $\mathrm{pH} 10$, con agitación constante por $2 \mathrm{~h}$. Luego de eliminar el filtro, se ajustó el pH a 7,0 (Wallis et al. 1979). Estos eluidos se usaron para inocular los diferentes cultivos celulares $(4 \mathrm{~mL})$ y para las reacciones de TR-RPC $(1 \mathrm{~mL})$.

\section{Cultivos celulares}

Los cultivos celulares (Instituto de Salud Pública, sección cultivos celulares) de células RD (rabdomiosarcoma), Hep-2 (carcinoma laríngeo), Vero (fibroblastos de riñón de mono) y L20B (células $\mathrm{L}$ recombinantes de ratón que expresan el receptor para poliovirus humano) (Pipkin et al. 1993) se hicieron crecer hasta confluencia en medio mínimo esencial Eagle, conteniendo $10 \%$ suero fetal bovino, $100 \mathrm{U} \mathrm{mL}^{-1}$ de penicilina y $100 \mu \mathrm{g} \mathrm{mL}^{-1}$ de estreptomicina en frascos y/o tubos de cultivo celular. Una vez alcanzada la confluencia, se mantuvieron en el mismo medio, pero conteniendo sólo $2 \%$ suero fetal bovino.

\section{Inoculación de las muestras de agua concentrada a cultivos celulares}

La inoculación se realizó en tubos de cultivo, en duplicado, en las cuatro líneas celulares mencionadas. Se utilizó $0,5 \mathrm{~mL}$ de muestra por tubo y se observó la evolución de los cultivos durante 15 días para observación de efecto citopático (EC).

\section{Virus Poliovacunal (Sabin)}

Se usó un extracto de virus poliovacunal (vacuna trivalente OPV), de concentración de $10^{8}$ ufp $\mathrm{mL}^{-1}$ (unidades formadoras de placas por $\mathrm{mL}$ ). Diluciones de este extracto se inocularon a los cultivos de células RD, Hep-2, Vero y L20B y se siguió la evolución por 15 días (controles positivos). Los controles con EC positivo, fueron procesados para inmunofluorescencia y evidenciados con anticuerpo monoclonal específico para enterovirus (Clon/Klon 5-D8/1 Dako). Para los controles negativos, la inoculación se hizo con tampón fosfato salino estéril.

Por otra parte, diluciones del extracto de virus poliovacunal ( 250 y $500 \mathrm{ufp}$ ) se utilizaron para inocular $2 \mathrm{~L}$ de agua potable y $2 \mathrm{~L}$ de agua del estero Laguna
Verde, simulando una infección. Estas muestras se concentraron y procesaron solo para las reacciones de TR-RPC.

\section{Extracción de RNA enteroviral}

Para la extracción del RNA enteroviral se utilizó Trizol LS (Gibco BRL) siguiendo las instrucciones del fabricante. El RNA obtenido se resuspendió en $50 \mu \mathrm{L}$ de agua milliQ estéril conteniendo dietilpirocarbonato (DEPC) al 0,01\% y se incubó a $55^{\circ} \mathrm{C}$ por 10 minutos. Si no era usado inmediatamente, era conservado a $-70^{\circ} \mathrm{C}$ hasta su uso.

\section{TR-RPC}

Para la amplificación de RNA enteroviral se usaron los partidores diseñados por Rotbart (1990) siguiendo el protocolo por él descrito. La amplificación se realizó en un termociclador MJ Research Inc, PTC 150, Hot bonnet. Con este procedimiento se obtuvo un amplificado de DNA de 154 pares de bases.

\section{Electroforesis en geles de agarosa}

La electroforesis se realizó en geles de agarosa (Ultrapure, Gibco) al $2 \%$ a la que se incorporó bromuro de etidio $\left(0,8 \mathrm{mg} \mathrm{L}^{-1}\right)$ para visualizar los productos de la amplificación. Se usó como referencia una escalera de DNA (Invitrogen) formada de 15 fragmentos romos de DNA, cuyos tamaños comprenden desde 100 a 1500 pares de bases. Los geles se fotografiaron sobre un transiluminador TM-36, UVP, Inc. con una cámara Polaroid Gel Cam DS-34 y película Polaroid 667.

\section{Resultados}

\section{Parámetros fisicoquímicos y metales}

La conductividad, dureza y sólidos totales de las muestras de agua del estero El Rosario (Parte Alta y Baja) fueron superiores a los de los otros esteros. En cambio, para todas las muestras el $\mathrm{pH}$ resultó ser levemente básico (Tabla 2). La concentración de los metales analizados se encontró dentro de la norma exigida para agua potable (INN 1984) y no se observaron resultados significativamente diferentes entre cada muestreo, con excepción de $\mathrm{Fe} \mathrm{y} \mathrm{Cu}$ de los esteros de Laguna Verde y de Quilpué respectivamente, cuyas concentraciones fueron aproximadamente tres a cuatro veces superior a la determinada en los otros esteros (Tabla 3 ).

\section{Inoculación de las muestras de agua concentrada a cultivos celulares}

Ninguna de estas muestras produjo efecto citopático positivo en los cultivos de células utilizados. Solo se observó este efecto en los controles de cultivo celular, 


\section{Tabla 2}

Parámetros fisicoquímicos de las muestras de agua

Physicochemical parameters of water samples

\begin{tabular}{lccccc}
\hline \multicolumn{1}{c}{ Muestra } & $\begin{array}{c}\text { Conductividad } \\
\left(\mathrm{mS} \mathrm{cm}^{-1}\right)\end{array}$ & $\mathrm{pH}$ & $\begin{array}{c}\text { Dureza Total } \\
\left(\mathrm{mg} \mathrm{L}^{-1}\right)\end{array}$ & $\begin{array}{c}\text { Sólidos totales } \\
\left(\mathrm{g} \mathrm{L}^{-1}\right)\end{array}$ & $\begin{array}{c}\text { Sólidos suspendidos } \\
\left(\mathrm{mg} \mathrm{L}^{-1}\right)\end{array}$ \\
\hline Tunquén (Sector Alto, 2001) & $0,54 \pm 0,04$ & $7,68 \pm 0,05$ & $125 \pm 6$ & $0,15 \pm 0,01$ & $28 \pm 3$ \\
Tunquén (Desembocadura, 2001) & $5,2 \pm 0,1$ & $8,29 \pm 6$ & $145 \pm 3$ & $0,02 \pm 0,01$ & $45 \pm 2$ \\
Viña del Mar, 2001 & $0,706 \pm 0,003$ & $7,59 \pm 0,02$ & $102 \pm 5$ & $0,55 \pm 0,04$ & $39 \pm 5$ \\
Quilpue, 2001 & $0,808 \pm 0,006$ & $7,77 \pm 0,07$ & $123 \pm 3$ & $0,70 \pm 0,03$ & $1,3 \pm 0,2$ \\
El Rosario (Parte Alta, 2002) & $33,1 \pm 0,1$ & $7,07 \pm 0,02$ & $1628 \pm 20$ & $23,3 \pm 0,4$ & $17,9 \pm 0,4$ \\
El Rosario (Parte Baja, 2002) & $33,4 \pm 0,2$ & $8,06 \pm 0,07$ & $1660 \pm 4$ & $22,5 \pm 0,1$ & $9,55 \pm 0,08$ \\
Laguna Verde (Puente Bajo, 2002) & $1,895 \pm 0,005$ & $7,73 \pm 0,05$ & $98 \pm 2$ & $11,6 \pm 0,2$ & $5,1 \pm 02$ \\
Laguna Verde (Puente los Azules, 2002) & $0,470 \pm 0,05$ & $7,60 \pm 0,05$ & $53 \pm 2$ & $2,4 \pm 0,2$ & $2,0 \pm 0,2$ \\
\hline
\end{tabular}

Tabla 3

Concentración total de algunos elementos determinados por ICP-OES en las muestras de agua del año 2002. [ $\mathrm{LD}(\mathrm{Pb})=2,5 \mu \mathrm{g} \mathrm{L}^{-1}$ y $\mathrm{LD}(\mathrm{Cu})=1,7 \mu \mathrm{g} \mathrm{L}^{-1}$ ]

Total concentration of some elements determined by ICP-OES in water samples of 2002. [LD $(\mathrm{Pb})=$ $2.5 \mu \mathrm{g} \mathrm{L}^{-1}$ and $\left.\mathrm{LD}(\mathrm{Cu})=1.7 \mu \mathrm{g} \mathrm{L}^{-1}\right]$

\begin{tabular}{lccccccc}
\hline \multicolumn{1}{c}{ MUESTRA } & \multicolumn{7}{c}{$\mathrm{C}_{\mathrm{M}}\left(\mu \mathrm{g} \mathrm{L} \mathrm{L}^{-1}\right)$} \\
& $\mathrm{Fe}$ & $\mathrm{Se}$ & $\mathrm{As}$ & $\mathrm{Zn}$ & $\mathrm{Pb}$ & $\mathrm{Cu}$ & $\mathrm{Cd}$ \\
\hline Viña del Mar & $28,1 \pm 0,6$ & $25 \pm 2$ & $17 \pm 1$ & $2,9 \pm 0,2$ & $4,6 \pm 1$ & $4,8 \pm 0,1$ & $4,1 \pm 0,1$ \\
Quilpué & $21,0 \pm 0,1$ & $28 \pm 6$ & $10,3 \pm 0,1$ & $5,7 \pm 0,1$ & $5,2 \pm 0,1$ & $15,9 \pm 0,2$ & $4,02 \pm 0,02$ \\
El Rosario (Parte Alta) & $21,0 \pm 0,1$ & $25,5 \pm 0,6$ & $24,2 \pm 0,3$ & $6,8 \pm 0,5$ & $<\mathrm{LD}$ & $<\mathrm{LD}$ & $4,3 \pm 0,1$ \\
El Rosario (Parte Baja) & $20,6 \pm 0,2$ & $11,6 \pm 0,1$ & $18,2 \pm 0,2$ & $6,3 \pm 0,2$ & $<\mathrm{LD}$ & $<\mathrm{LD}$ & $4,9 \pm 0,2$ \\
Laguna Verde (Puente Bajo) & $60,5 \pm 0,4$ & $26 \pm 3$ & $12,3 \pm 0,6$ & $5,5 \pm 0,5$ & $4,8 \pm 0,2$ & $3,9 \pm 0,3$ & $4,3 \pm 0,1$ \\
Laguna Verde (Puente los Azules) & $88,2 \pm 0,4$ & $21,1 \pm 0,6$ & $14,0 \pm 0,9$ & $5,5 \pm 0,6$ & $6,7 \pm 0,1$ & $3,3 \pm 0,2$ & $4,4 \pm 0,1$ \\
\hline
\end{tabular}

inoculados con diluciones del extracto de virus poliovacunal.

\section{Amplificación del RNA enteroviral de las muestras de agua concentradas}

Ninguna de las muestras de los esteros dio reacción positiva (amplificado de DNA de 154 pares de bases). Sólo fueron positivas las muestras concentradas de agua potable y agua del estero Laguna Verde, previamente inoculadas con virus poliovacunal (Fig 1). La menor concentración de virus poliovacunal con la que se realizó la simulación de infección y se obtuvo reacción positiva fue usando 250 ufp en $2 \mathrm{~L}$ de agua potable (Fig. 1, canal 3). Para el estero Laguna Verde solo se obtuvo amplificación, al usar 500 ufp en $2 \mathrm{~L}$ de agua (Fig. 1, canales 7 y 8$)$.

\section{Discusión}

Los virus entéricos infecciosos, particularmente los enterovirus, se han aislado desde diferentes tipos de agua, por ejemplo subterráneas, residuales tratadas, marinas, de ríos, de arroyos y potable (Lee \& Kim 2002). Diversos factores influyen en el hallazgo y supervivencia de estos virus en el agua. Entre éstos, la temperatura, los sólidos suspendidos, la turbulencia, la intensidad del sol, las excreciones vertidas y los nutrientes, todos los cuales se deben considerar cuando se intenta predecir la presencia de patógenos virales en el agua (Lipp et al. 2001). Los virus entéricos pueden sobrevivir en el ambiente en un amplio rango de $\mathrm{pH}$ (3 a 10) y por períodos largos, a baja temperatura. En verano y a principios del otoño se acrecientan las infecciones enterovirales en humanos, lo que coincide con un aumento de actividades acuáticas 


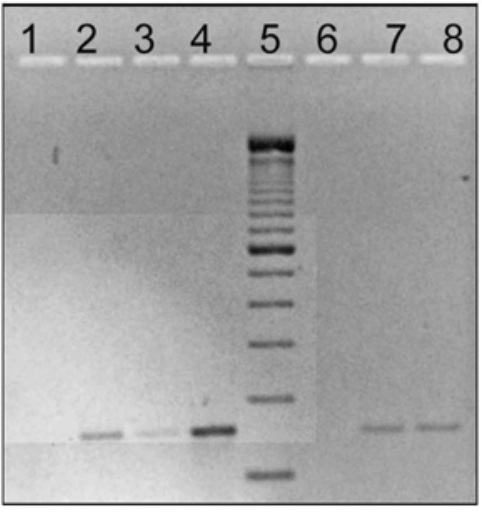

Canal 1: Control negativo de agua potable; Canal 2: TR-RPC de RNA enteroviral de agua potable (500 ufp virus poliovacunal en $2 \mathrm{~L}$ ); Canal 3: TR-RPC de RNA enteroviral de agua potable (250 ufp de virus poliovacunal en $2 \mathrm{~L}$ ); Canal 4: TR-RPC de RNA enteroviral de extracto de virus poliovacunal (control positivo); Canal 5: Escalera de DNA de 100 pares de bases; Canal 6: Control negativo de agua del estero Laguna Verde, Puente Bajo; Canal 7: TR-RPC de RNA enteroviral de Laguna Verde, Puente Bajo (500 ufp de virus poliovacunal en 2 L); Canal 8: TR-RPC de RNA enteroviral de Laguna Verde, Puente Los Azules (500 ufp de virus poliovacunal en $2 \mathrm{~L}$ )

\section{Figura 1}

\section{TR-RPC de las muestras de agua potable y del estero} Laguna Verde inoculadas con virus poliovacunal

RT-PCR of drinking water and water from the Laguna Verde stream inoculated with poliovacunal virus

recreacionales y contacto con el agua (Koewa-Haluch 2001).

La imposibilidad de estudiar todos los patógenos virales en un análisis ambiental ha hecho necesario buscar organismos indicadores de calidad del agua (Fong \& Lipp 2005). Entre los grupos de virus entéricos más estudiados con este potencial, están los enterovirus, los que elegimos para realizar este estudio. Éstos han sido ampliamente usados para evaluar los riesgos asociados con la transmisión de virus infecciosos, así como para identificar la fuente dominante de contaminación fecal en aguas.

Los virus, por encontrarse muy diluidos en el ambiente acuático, se deben concentrar para analizarlos ya sea mediante inoculación a cultivos celulares o por métodos moleculares. Existe una gran variedad de métodos para concentrarlos (Bosch 1998), entre ellos la precipitación con sales de $\mathrm{MgCl}_{2}$ y $\mathrm{Al}\left(\mathrm{NO}_{3}\right)_{3}$ que presentamos en este trabajo (Wallis et al. 1979). Los resultados obtenidos para las muestras de agua concentradas de los diferentes esteros, por inoculación a cultivos celulares y por TR-RPC son coincidentes (ausencia de enterovirus).

Una razón para usar cultivos celulares, es que permiten detectar virus infeccioso, a diferencia del diagnóstico molecular con TR-RPC que siendo más sensible, rápido y específico, sólo detecta presencia del ácido nucleico viral. Puesto que no todos los enterovirus crecen en cultivos celulares o bien si se multiplican en éstos, pueden no producir efecto citopático, usamos cuatro líneas celulares. No obtuvimos EC positivo con ninguno de los esteros, por ello el cultivo celular integrado a la TR-RPC sería otra opción recomendada para abordar este tipo de análisis (Chapron et al. 2000).

Tomando en cuenta estos resultados, fue pertinente considerar la medición de algunos parámetros fisicoquímicos y la determinación de la concentración de algunos metales (Tablas 2 y 3 ), como marco referencial en este estudio. Las muestras de agua se concentraron unas 400 veces y era preciso descartar un efecto tóxico de algún componente de la muestra sobre los cultivos celulares o una inhibición de las reacciones de TR-RPC.

Dos muestras del estero de Laguna Verde (Puente Bajo y Los Azules) junto con una muestra de agua potable, fueron aquellas en que se realizó la simulación de la infección y la detección de virus entéricos por TR-RPC. Los resultados positivos (Fig. 1) indican ausencia de compuestos tóxicos que inhiban en esta reacción. Sin embargo, el haber obtenido resultado positivo en el estero Laguna Verde solamente con 500 ufp y no con 250 ufp sugiere una disminución de la sensibilidad en la reacción de TR-RPC. No podemos afirmar, pero tampoco descartar la influencia de Fe (Tabla 3) presente en estas aguas, en este resultado.

Como conclusión, la metodología utilizada en este trabajo no permitió detectar enterovirus en estas aguas naturales de Valparaíso. Sin embargo, no se descarta la posibilidad que los contengan. No existe precedente de análisis de estos patógenos en estos cursos de agua. Con los resultados acá obtenidos no es posible afirmar que estos cursos hídricos estén libres de enterovirus.

\section{Agradecimientos}

Trabajo financiado por la Dirección de Investigación y Desarrollo de la Universidad de Valparaíso, Proyecto DIPUV 04/2001. Se agradece a los académicos de la Universidad de Valparaíso, Dr. Sergio Zunino, quien realizó los muestreos y Dra. Caroline Weinstein por la lectura crítica de este trabajo. Expresamos finalmente, nuestro reconocimiento y agradecimiento a los evaluadores anónimos por sus sugerencias y comentarios. 


\section{Literatura citada}

Abbaszadegan M. 2001. Advanced detection of viruses and protozoan parasites in water. Reviews in Biology and Biotechnology 2: 21-26.

Bosch A. 1998. Human enteric viruses in the water environment: a minireview. International Microbiology 1: 191-196.

Chapron CD, NA Ballester, JH Fontaine, CN Frades \& AB Margolin. 2000. Detection of astroviruses, enteroviruses and adenovirus types 40 and 41 in surface waters collected and evaluated by the information collection rule and an integrated cell culture-nested PCR procedure. Applied and Environmental Microbiology 66: 2520-2525.

Fong TT \& EK Lipp. 2005. Enteric viruses of human and animals in aquatic environments: health risks, detection and potential water quality assessment tools. Microbiology and Molecular Biology Reviews 69(2): 357-371.

Griffin DW, EK Lipp, MR McLaughin \& JB Rose. 2001. Marine recreation and public health microbiology: request for the ideal indicator. BioScience 51: 817-825.

INN. 1984. Normas oficiales para la calidad del agua. Chile. Norma Chilena Oficial 409/1.Of.84. Agua potable - Parte 1: Requisitos, 11 pp. Instituto Nacional de Normalización, Santiago de Chile.

INN. 1996. Norma Chilena Oficial NCh 410 Of. 96 . Calidad del agua - Vocabulario, 73 pp. Instituto Nacional de Normalización, Santiago de Chile.

Keswick BH, CP Gerba, HL DuPont \& JB Rose. 1984. Detection of enteric viruses in treated drinking water. Applied and Environmental Microbiology 47: 1290-1294.

Koewa-Haluch R. 2001. Waterborne Enterovirus as a hazard for human health. Polish Journal of Environmental Studies 10(6): 485-487.
Lee SH \& SJ Kim. 2002. Detection of infectious enteroviruses and adenoviruses in tap water in urban areas in Korea. Water Research 36(1): 248-256.

Lipp EK, R Kurz, R Vincent, C Rodriguez-Palacios, SR Farrah \& JB Rose. 2001. The effects of seasonal variability and weather on microbial fecal pollution and enteric pathogens in a subtropical estuary. Estuaries 24: 266-276.

Muller-Wegener U. 1988. Interaction of humic substances with biota. En: Frimmel FH \& RF Christman (eds). Humic substances and their role in the environment, pp. 179-192. John Wiley and Sons, New York.

Pipkin PA, DJ Wood, VR Racaniello \& PD Minor. 1993. Characterization of $\mathrm{L}$ cells expressing the human poliovirus receptor for the specific detection of poliovirus in vitro. Journal of Virological Methods 41: 333-340.

Rotbart HA. 1990. Enzymatic RNA amplification of the Enterovirus. Journal of Clinical Microbiology 28(3): 438442.

Skraber S, B Gassilloud, L Schwartzbrod \& C Gantzer. 2004. Survival of infectious Poliovirus-1 in river water compared to the persistence of somatic coliphages, thermotolerant coliforms, and Poliovirus-1 genome. Water Research 38: 2927-2933.

Straub TM \& DP Chandler. 2003. Towards a unified system for detecting waterborne pathogens. Journal of Microbiological Methods 53: 185-197.

Vinatea EB, TCM Sincero, CMO Simoes \& CRM Baradi. 2006. Detection of poliovirus type 2 in oyster by using cell culture and RT-PCR. Brazilian Journal of Microbiology 37: 64-69.

Wallis C, JL Melnick \& CP Gerba. 1979. Concentration of viruses from water by membrane chromatography. Annual Review of Microbiology 33: 413-437. 